\title{
BRANDING "SIAK THE TRULY MALAY" OLEH DINAS PARIWISATA KABUPATEN SIAK
}

\author{
$\operatorname{Artis}^{1}$ \\ ${ }^{1}$ Dosen Ilmu Komunikasi Fakultas Dakwah dan Komunikasi, \\ Universitas Islam Negeri Sultan Syarif Kasim Riau \\ Jl. HR Soebrantas Km 15 Simpangbaru, Tampan, Pekanbaru 28293
}

Email:artis@uin-suska.ac.id

\begin{abstract}
Abstrak
Dinas Pariwisata KabupatenSiak mengusung sebuah brand daerah yaitu Siak The Truly Malay pada tanggal 11 Maret 2013 di Siak. Untuk menunjukkan dan mempertegas image bahwa Siak memiliki sebuah identitas di bidang Pariwisata yang berbasis Budaya Melayu. Untuk itu kegiatan branding pun dilakukan oleh Dinas Pariwiwisata khususnya bagian Pemasaran dengan berbagai strategi untuk memperkenalkan brand tersebut kepada masyarakat. Selama ini branding yang sudah dijalankan oleh Dinas Pariwisata belum terbilang efektif, karena branding yang dijalankan baru sebatas melalui media massa dan sosial. Rumusan masalah penelitian ini adalah Bagaimanakah Branding Siak The Truly Malay dilaksnakan oleh Dinas Pariwisata Kabupaten Siak. Penelitian ini bertujuan untuk mengetahui BrandingSiak The Truly Malay yang di jalankan oleh Dinas Pariwisata Kabupaten Siak. Penelitian ini menggunakan pendekatan Branding dengan teknik pengumpulan data menggunakan wawancara dan dokumentasi.. Hasil penelitian menunjukkan bahwa kegiatan branding bertujuan untuk mengenalkan brand Siak The Truly Malay agar kahalayak sadar akan adanya brand tersebut dengan menggunakan pendekatan branding yang terdiridari 6 indikator yaitu 1) brand Awareness (menciptakan kesadaran): Nuansa Melayu yang ditandai dengan Istana Siak, masyarakat dan tokoh kepentingan berbusana Melayu, permainan rakyat dan kegiatan berbasis budaya Melayu 2) brand Association (ingatan mengenai merk) yang sangat mudah untuk di ingat oleh khalayak yaitu simbol Istana Kerajaan. 3)brand Identity, (identitasmerk): Melayu yang sebenarnya. 4) brand Image (citra) : Siak sebagai jiwanya Melayu. 5) brand Personality (kepribadian merk): karakteristiknya yaitu busana Melayu, bahasa Melayu, pemakaian Tanjak Melayu. 6)brand Equity (kekuatan merk): lebih unik dari segi desainnya karena menampilkan tagline disertai dengan gambar atau simbol. Metode yang digunakan dalam penelitian ini adalah Kualitatif Deskriptif.
\end{abstract}

Kata Kunci : Branding, Siak, The Truly Malay,

\section{Pendahuluan}

Kebudayaan dan adat istiadat suatu daerah sudah menjadi destinasi utama bagi pemerintah setempat yang menggaungkan kebudayaan dan adat istiadat tempat ia memerintah untuk menarik minat wisatawan baik dari dalam, luar kota hingga wisatawan mancanegara untuk datang ke daerahnya. Salah satunya yaitu pemerintah di Kabupaten Siak berawal pada tahun 2013 memperkenalkan Brand yang berbunyi "Siak The Truly Malay" pada even Tour de siak 2013. Berangkat dari Rekomendasi dokumen pengembangan pariwisata dan tuntunan dalam kemajuan pariwisata kekinian yang di ajukan oleh pihak Dinas pariwisata dalam rangka membentuk brand Images Siak sebagai daerah tujuan utama di Riau dan di 
Indonesia maka icon Siak sebagai pusat budaya Melayu di Indonesia perlu di munculkan branding "Siak The Truly Malay", seacara otomatis masuk program pengembangan dan tidak secara detail masuk dalam penganggaran. ${ }^{1}$

Arah visioner mewujudkan Kabupaten Siak sebagai pusat kebudayaan Melayu di Indonesia tahun 2025, adalah dengan meningkatkan pelibatan masyarakat untuk secara bersama menggali, membangun, dan mengembangkan kampung-kampung lama Melayu, demikian pula dengan kampung suku Asli (Sakai dan Akit). Kuatnya akar budaya Melayu tidak sekedar menopang kehidupan masyarakat, tetapi menjadi penguat karakter bangsa untuk menyikapi intervensi budaya asing yang tidak sesuai dengan kepribadian bangsa.Pelibatan masyarakat sebagai pendukung kebudayaan Melayu menjadi sangat penting. $^{2}$

Sesuai dengan visi dan misi Kabupaten Siak, yaitu mewujudkan masyarakat Siak yang sehat, cerdas dan sejahtera dalam lingkungan masyarakat yang agamis dan berbudaya Melayu serta mewujudkan pelayaan publik terbaik, pemerintah menekankan beberapa program yang sudah dan sedang dilaksanakan. Bahkan Pemerintah yang menyadari potensi Siak yang kaya akan nilai-nilai tradisi, sejarah, dan budaya, pemerintah telah mengusulkan daerah ini sebagai kawasan heritage city atau kota yang memiliki kekayaan budaya dan sejarah yang harus dilestarikan. ${ }^{3}$

Dinas Pariwisata Kabupaten Siakberperan penting dalam merupakan bagian dalam melakukan branding Pariwisata "Siak The Truly Malay" kepada masyarakat karena di Kabupaten Siak terdapat situs-situs sejarah, kebudayaan, kerajinan Melayu, dan hal-hal menarik seputar Melayu terdapat di daerah Siak . Tujuannya agar Kabupaten Siak menjadi destinasi wisata utama di Riau yang semakin ramai dikunjungi wisatawan baik dari dalam maupun luar negeri.

Tabel 1.1

Data Pengunjung di Kabupaten Siak Tahun 2010-2015

\begin{tabular}{|l|l|l|l|}
\hline NO & TAHUN & DOMESTIK & MANCANEGARA \\
\hline & & & \\
1 & 2010 & 30.432 & 52 \\
2 & 2011 & 40.724 & 139 \\
3 & 2012 & 52.891 & 151 \\
4 & 2013 & 45.794 & 182 \\
5 & 2014 & 49.925 & 280 \\
6 & 2015 & 42.353 & 269 \\
\hline
\end{tabular}

Tabel 1.1 ini Menjelaskan bahwa terjadi turun naik jumlah pengunjung dari tahun 2010 sampai 2012 yang berdatangan ke kabupaten siak tepat sebelum brand di usungkan pada tahun 2013. Kabupaten Siak mengalami peningkatan pengunjung dengan jumlah paling besar sebelum brand Siak The Truly Malay di kenalkan yaitu pada tahun 2012 sebanyak 52.891 Domestik dan 151 Mancanegara. Kemudian pada tahun 2013 brand tersebut mulai di kenalkan, terjadi turun naik peningkatan jumlah pengujung pada bagian Domestik.Akan

\footnotetext{
${ }^{1}$ DinasPariwisataPemudadanOlahragaKabupatenSiak..Kajian Pengembangan Objek Pariwisata Unggulan di Kabupaten Siak. (Pekanbaru.PT.WastuAsrindo Riau, 2012).9

${ }^{2}$ http://mediacenter.riau.go.id/read/7659/bupati-promosikan-siak-the-truly-malay.html diakses pada tanggal 11 januari 2017 pukul 10:28 Wib

${ }^{3}$ http://mediacenter.riau.go.id/read/7659/bupati-promosikan-siak-the-truly-malay.html diakses pada tanggal 11 Januari 2017 pukul 10:28 Wib

${ }^{4}$ Dinas Pariwisata Kabupaten Siak. Data Jumlah Kujungan di Siak.Data Prariset Berbentuk PowerPoint. 11 januri 2017
} 
tetapi tidak pada pengunjung yang berasal dari Mancanegara, data menunjukkan bahwa wisatawan melaju naik pada tahun 2014 karena itu merupakan tahun kedua brand dikenalkan.Hingga tahun 2015 wisatawan Mancanegara mengalami penurunan tidak terlalu drastis.

Menurut hasil prariset branding Siak The Truly Malay yang dilaksanakan oleh dinas pariwisata kabupaten siak baru sebatas melalui Fasilitas Umum, dengan menggunakan media neon box, videotron, banner, bilboard dan stiker. Transpotasi Massa, bahan pemasaran dapat berupa Stiker, Majalah Pariwisata Siak, Tvc dan lain-lain. Sosial Media,Media Cetak \& Digital, Media yang digunakan dapat menampilkan logo "Siak The Truly Malay", profil pariwisata siak, video promosi pariwisata siak.. ${ }^{5}$ Akan tetapi sampai saat ini branding Siak The Truly Malay belum terlalu melekat atau familiar di telinga masyarakat, untuk mengetahui lebih lanjut maka dari itu diperlukan penelitian yang lebih mendalam terkait Branding "Siak The Truly Malay"

Dengan menerapkan branding "Siak The Truly Malay", diharapkan mampu membangun identitas yang jelas, asosiasi yang kuat, dan menyematkan atribut positif agar mampu menempatkan diri dan memenangkan persaingan kota lainnya. Berbagai kegiatan penunjang pembentukan branding dapat dilakukan melalui penyelenggaraan berbagai event yang berbasis budaya Melayu seperti, festival budaya Melayu, festival kuliner Melayu, kesenian Melayu dan lainnya. ${ }^{6}$

Berdasarakan fenomena diatas, maka penulis tertarik untuk mengadakan penelitian pada Dinas Pariwisata Kabupaten Siak dengan judul "Branding "Siak The Truly Malay" oleh Dinas Pariwisata Kabupaten Siak”

\section{Rumusan Masalah}

Pokok permasalahan yang akan diteliti secara ilmiah adalah Bagaimana Startegi Branding Siak The Truly Malay Oleh Dinas Pariwisata Kabupaten Siak?

\section{Tujuan dan Kegunaan Penelitian}

Sesuai dengan rumusan masalah, maka tujuan dari penelitian ini adalah untuk mengetahui Brandin "Siak The Truly Malay" yang di laksanakan oleh Dinas Pariwisata Kabupaten Siak dan kegunaan penelitian ini sebagai acuan untuk sarana tentang perencanaan komunikasi yang tepat untuk membangun relations yang baik dalam melakukan strategi branding "Siak The Truly Malay". Serta dapat memberikan input bagi pemerintah Kabupaten Siak guna menentukan kebijakan-kebijakan untuk meningkatkan kegiatan sosialisasi atau memperkenalkan "Siak The Truly Malay"di mata dunia sehingga dapat menciptakan hal-hal menarik dan berkualitas dalam kegiatan branding.

\section{Metode Penelitian}

Berdasarkan permasalahan dan tujuan penelitian yang telah dirumuskan, maka jenis penelitian ini dalam bentuk deskriptif kualitatif. Penelitian deskriptif kualitatif merupakan salah satu jenis penelitian yang bertujuan mendeskripsikan secara sistematis dan faktual mengenai fakta-fakta dan menggambarkan fenomena secara detail, dimana metode penelitian kualitatif ini dilaksanakan dengan menggunakan data yang dicatat bukan dengan angkaangka tetapi menggunakan klarifikasi-klarifikasi yang dipaparkan secara deskriptif.Sumber data terdiri dari data primer dan data sekunder. Data primer merupakan data yang

\footnotetext{
${ }^{5}$ Dinas Pariwisata Kabupaten Siak. Strategi Branding Siak The Truly Malay. Data Prariset Berbentuk PowerPoint. 11 januari 2017

${ }^{6}$ DinasPariwisataPemudadanOlahragaKabupatenSiak..Kajian Pengembangan Objek Pariwisata Unggulan di Kabupaten Siak. (Pekanbaru.PT.WastuAsrindo Riau, 2012).9
} 
dikumpulkan oleh peneliti yang berasal dari sumbernya langsung, yang didapat dengan wawancara semi terstruktur, tak terstruktur, dan dokumentasi dan data sekunder diambil dari buku, majalah, jurnal, media sosial dan teknik pengumpulan data dengan observasi, yaitu kegiatan yang dilakukan oleh penulis dalam melakukan penelitian dengan cara mencatat secara sistematis terhadap gejala-gejala yang terdapat pada objek penelitian.Wawancara, yaitu sejumlah pertanyaan yang diajukan untuk mengetahui branding Siak The Truly Malay yang dlaksanakan oleh Dinas Pariwisata Kabupaten Siak dan dokumentasi yaitu kegiatan pencatatan pengumpulan dokumen atau berkas yang penting yang masih berhubungan dengan penelitian.

Selanjutnya analisis data merupakan bagian yang amat penting dalam metode ilmiah, karena dengan analisis data tersebut dapat diberi arti dan makna yang berguna dalam memecahkan masalah penelitian.Penelitian ini adalah penelitian yang bersifat deskriptif kualitatif yaitu menggambarkan atau memaparkan fenomena-fenomena dengan kata-kata atau kalimat, kemudian data-data tersebut dianalisis untuk memperoleh kesimpulan.

\section{Hasil Penelitian}

Penjelaskan hasil penelitian yang didapat dari proses wawancara kepada informan bahwa Branding Siak The Truly Malay muncul semenjak adanya kajian pengembangan objek pariwisata unggulan kabupaten siak tahun 2012, didalamnya berbagai macam rekomendasi yang di ajukan salah satunya yaitu untuk segera membuat branding Siak The Truly Malay, harapannya animo wisatawan untuk berkunjung ke Siak salah satunya dipacu oleh keinginan untuk menyaksikan bagaimana budaya melayu itu yang sesungguhnya, di aplikasikan melalui penyelenggaraan berbagai event yang berbasis budaya melayu. Ada 6 konsep yang menjadi branding yang digunakan dalam penelitian ini:

\section{Brand Awareness}

Brand Awareness di definisikan sebagai Kekuatan dan kesadaran dari kehadiran brand dalam benak pelanggan atau pengguna. Brand ini menjadi nilai kekuatan dari brand Siak The Truly Malay yaitu bahwa Siak merupakan bekas kerajaan Melayu yang termashur dari dahulu hingga sekarang sehingga layak dikenalkan ke khalayak ramai, jadi dari sisi kemelayuanlah yang menjadi sisi kekuatan dari brand tersebut. ${ }^{7}$

Nilai kekuatan dari brand Siak The Truly Malay adalah budaya melayu yang masih kental yang sudah ada sejak zaman kerajaan hingga sekarang. Hal ini dibuktikan dengan berdirinya Istana Siak yang merupakan sejarah kebesaran kerajaan Melayu Islam yang terbesar di Riau. Dengan kekuatan inilah Dinas Pariwisata Kabupaten Siak memunculkan icon Siak sebagai pusat budaya Melayu di Indonesia yaitu brand Siak The Truly Malay yang layak di kenalkan ke khalayak, sehingga animo wisatawan untuk berkunjung ke Siak salah satunya di pacu oleh rasa penasaran dan keinginan untuk menyaksikan bagaimana budaya melayu yang sesungguhnya dengan tujuan untuk menjadikan Siak sebagai daerah tujuan wisata utama di Riau dan di Indonesia.

\section{Brand Association}

Brand Association atau ingatan mengenai merek yang terbentuk dalam benak pelanggan diperkenalkan melalui atribut, endorser, atau simbol-simbol.

"Sampai saat ini Dinas Pariwisata belum ada menggunakan endorse seperti artis-artis untuk melakukan sosisalisasi brand ini, branding masih dilakukan dengan cara mandiri seperti melalui medsos, media cetak. Untuk daerah siak sendiri kerja sama

\footnotetext{
${ }^{7}$ Hasil wawancara dengan Kepala Bidang PemasaranDinas Pariwisata Siak Bapak BasriansyahPada tanggal 19 Juli 2017 di Siak
} 
dengan bujang dara yang terpilih untuk membantu mensosialisasikan brand tersebut melalui berbagai macam kegiatan-kegiatan pariwisata, kemudian dari kesadaran masyarakat sendiri yang senang dengan brand daerah sendiri sehingga mereka tidak enggan untuk meng-explore brand ini dengan cara mereka sendiri. Seluruh instansi pemerintah juga tak luput dari hal ini, mereka juga melakukan branding kepada khlayak.",

Dalam melakukan branding Dinas Pariwisata tidak ada menggunakan endorse melalui pihak manapun, Dinas Pariwisata masih melakukan branding secara mandiri yaitu melalui media cetak, digital, soisal, event kapariwistataan dan intasi pemerintahan setempat. Kemudian didukung juga oleh masyarakat setempat yang merasa peduli dengan daerah mereka sendiri seperti masyarakat sadar wisata sehingga mereka termotivasi sendiri untuk mengexplore daerah mereka kepada khalayak ramai.

\section{Brand Identity}

Brand Identity merupakan identitas dari sebuah merk yang dimiliki yang harus dibentuk dan dipelihara. Asosiasi ini merepresentasikan apa yang di wakili oleh brand dan mengimplikasikan janji kepada pelanggan dan organisasi.

"Dengan adanya istana siak dan daun sirih itu sudah melambangkan identitas Melayu.Kehidupan sehari-hari masyarakat siak yang menggambarkan masyarakat melayu sudah diaplikasikan sejak zaman dahulu seperti pada saat berinteraksi dengan sesama masyarakat siak menggunakan bahasa melayu, berpakaian melayu dan termasuk dalam upacara adat pernikahan ala melayu hingga sekarang." 9

Brand Siak The Truly Malay sudah sangat menggambarkan identitas Melayu yang ada didaerah siak. hal ini dapat dilihat dari bentuk modifikasi brand yang di rancang sendiri oleh pihak Dinas Pariwsata Siak. Setiap icon yang terdapat dalam brand tersebut sarat akan makna melayu yang masih terjaga dan berjalan dengan baik. Seperti lambang istana, ini merupakan salah satu situs sejarah bekas Kerajaan Melayu terbesar yang ada di Siak.

\section{Brand Image}

Brand image merupakan bagaimana citra sebuah brand tersebut di persepsikan oleh khalayak dan organisasi.

"Image yang akan di capai yaitu image melayu yang betul-betul kental yang masih ada di siak, sekarang setiap kegiatan-kegiatan yang di laksanakan ada unsure budaya melayunya. Memang untuk saat ini masih belum maksimal Karena baru beberapa tahun memperkenalkan brand ini, mudah-mudahan kedepannya kita bertahap memperkenalkan brand ini sehingga brand ini menjadi brand yang dikenal seperti brand di kota-kota lainnya yang sudah terkenal seperti brand Jogja Never Ending Asia, Solo Spirit Of Java, dan brand Pesona Indonesia yang tujuanya untuk meningkatnya jumlah wisatawan yang datang ke Siak."10

Dinas Pariwisata menargetkan pencapaian Image Melayu. Meskipun image daerah siak sebagai peradaban Melayu yang bisa terkenal kepelosok tanah air dan mancanegara.

\section{Brand Personality}

Brand personality merupakan seperangkat karakteristik manusia atau kepribadian sebuah merk yang diasosiasikan dengan sebuah brand.

\footnotetext{
${ }^{8}$ Wawancara dengan Kepala Bidang PemasaranDinas Pariwisata Siak Bapak BasriansyahPada tanggal 19 Juli 2017 di Siak

${ }^{9}$ Wawancara dengan Kepala Bidang PemasaranDinas Pariwisata Siak Bapak BasriansyahPada tanggal 19 Juli 2017 di Siak

${ }^{10}$ Wawancara dengan Seksi PemasaranDinas Pariwisata Siak BapakMuhammad Azni pada tanggal 19 Juli 2017 di Siak
} 
"Yang membedakan dengan brand daerah lainnya yaitu dari segi gambar Istana Siak dan Daun Sirih, pemilihan warna, dan kalimat yang menjelaskan image melayu. setiap daerah memiliki kekhasan tersendiri seperti di Bukittinggi terkenal dengan Jam Gadang dan panorama alamnya, Jakarta dikenal dengan monas dan Siak dikenal dengan istananya. Berdasarkan survey belum ada daerah manapun yang memiliki karakteristik yang sama dengan brand daerah Siak baik dari sisi lambang istana dan daun sirih maupun kalimatnya. Jadi setiap daerah memiliki kekhasan masing-masing yang keunikannya juga berbeda." 11

Yang membedakan brand Siak The Truly Malay dengan brand daerah lainnya yang menjadikan brand daerah siak ini unik yaitu dari sisi gambar yang di tampilkan yaitu Istana Kerajaan dan Daun Sirih, selanjutnya dilihat dari sisi pemilihan warna yang di tampilkan pada modifikasi daun sirih dan kalimat Siak The Truly Malay memiliki makna bagaimana kehidupan masyarakat melayu. Kemudian makna dari kalimat Siak The Truly Malay yang memiliki maksud dan arti yang unik dan berbeda dari daerah lain juga merupakan karakteristik yang di unggulkan

\section{Brand Equity}

Brand Equity merupakan seperangkat asset (dan liabilitas) yang terkait dengan simbol brand yang menjadi kekuatan untuk menambah atau mengurangi nilai yang dimiliki oleh produk dan jasa dari perusahaan tersebut.

"Branding tidak hanya di lakukan di siak saja, akan tetapi juga didaerah lain khususnya di seluruh daerah provinsi riau, kemudian memasang stiker di mobil yang menyatakan ini adalah brand dari siak, kemudian pernah memasang spanduk pada tahun 2014 di bandara SSQ, Soekarno Hatta di Jakarta, di pelabuhan Sungai Duku, beberapa titik dijalan Jendral Sudirman dan tempat-tempat strategis yang banyak khalayak akan membacanya, akan tetapi setahun belakangan ini kurang berjalan karena terkendala pada biaya. Tak ketinggalan juga melakukan branding melalui media sosial, baik itu menampilkan gambar brand Siak The Truly Malay, foto dan video-video yang berkaitan dengan wisata budaya melayu",12

Penyusunan strategi yang sudah dilakukan oleh pihak Dinas Pariwisata antara lain yaitu mensosialisaikan brand tersebut didalam dan daerah-daerah lain, menampilkan stiker di mobil-mobil pribadi dan dinas pemda, memajangkan spanduk dan baliho di tempat yang strategis, mengaplikasikannya melalui kegiatan pemda, kemudian selalu menginformasikan kepada media cetak dan online.

\section{Pembahasan}

Adapun teknik yang digunakan untuk mendapatkan data adalah observasi, wawancara, dan dokumentasi guna mengetahui Strategi Branding Siak The Truly Malay yang dilaksanakan oleh Dinas Pariwisata Kabupaten Siak melalui beberapa strategi yang dimanfaatkan dalam kegiatan branding yaitu mengacu pada konsep brand Awareness, Association, Identity, Image, Personality, dan Equity.

\section{Brand awareness}

Brand awarenessdiartikan sebagai kesanggupan seorang calon pembeli untuk mengenali, mengingat kembali suatu merek sebagai bagian dari suatu kategori produk

\footnotetext{
${ }^{11}$ Wawancara dengan Seksi PemasaranDinas Pariwisata Siak BapakMuhammad Azni pada tanggal 19 Juli 2017 di Siak

${ }^{12}$ Wawancara dengan Seksi PemasaranDinas Pariwisata Siak BapakMuhammad Azni pada tanggal 19 Juli 2017 di Siak
} 
tertentu. ${ }^{13}$ Budaya Melayu yang masih kental dan sudah ada sejak zaman kerajaan hingga sekarang merupakan sebuah tombak yang menjadi kekuatan dari brand STTM bagi Dinas Pariwisata untuk menumbuhkan kesadaran khalayak.Hal ini dibuktikan dengan berdirinya Istana Siak yang merupakan sejarah kebesaran kerajaan Melayu Islam yang terbesar di Riau.

Dinas Pariwisata menerapkan strategi brandingnya untuk meperkenalkan brand tersebut dengan cara menggunakan berbagai media. Media yang digunakan yaitu media cetak (koran, barosur, leaflet, buku profil pariwisata, spanduk, stiker, pamphlet dan lainnya), media sosial (facebook, twitter, instagram, Web, YouTube). Dengan tujuan agar masyarakat kenal Kabupaten Siak sudah memiliki brand daerah yang unik dan layak untuk dijadikan destinasi wisata utama tingkat Provinsi Riau maupun di Indonesia.

Kemudian untuk menumbuhkan kesadaran masyarakat untuk mengenali brand tersebut Dinas Paiwisata juga melakukan branding melalui event-event kebudayaan dan olahraga, seperti festival Zapin Nusantara yang mencakup beberapa Negara, kemudian festival Siak Bermadah, festival Kuliner Melayu, Pawai Budaya Tingkat Nasional dan Internasional, festival Gasing Internasional, Tourde Siak, BMX Asian, Sepatu Roda dan lainnya. Upaya yang dilakukan oleh Dinas Pariwisata dalam mengenalkan brand tersebut membuahkan hasil yang lumayan memuaskan.Salah satunya brand STTM sudah hampir di kenal oleh masyarakat Provinsi Riau, Indonesia dan mancanegara.

Kegiatan branding yang dilakukan Dinas Pariwisata dalam mengexplore segala potensi yang terdapat di siak dilakukan mulai dari pukul 7.00 wib, mereka memilih dimulai dari pagi hari karena pada saat itu rata-rata khalayak sedang memegang gadget atau sedang mengakses akun sosial mereka masing-masing. Kemudian dilanjutkan pada siang hari yaitu pada pukul 12.00 wib yaitu pada jam makan siang, terakhir pukul 19.00 malam karena khalayak sudah berada di tempat masing-masing yang sudah terlepas dari kesibukan kerja atau lainnya dan tentunya lebih banyak khalayak yang mengakses media soisal mereka.

Untuk akun pada Fecebook Dinas Pariwisata di mulai awal tahun 2017 tanggal 23 bulan Januari, halaman facebook Dinas Pariwisata ini memiliki sebanyak 63 orang pengikut dan 62 orang yang menyukai. Pada tanggal 11 Agustus halaman tersebut baru melakukan kegiatan branding dengan jumlah 19 postingan, dua diantaranya dalam bentuk video. Satu kali postingan memiliki nilai like paling tinggi dari para pengikut sebanyak 3 kali like, untuk postingan video memiliki jumlah tanyang sebanyak 13 kali.

Untuk ukuran akun milik Dinas Pemkab Jumlah follower dan like sebanyak tersebut tidaklah merupakan hal yang memuaskan, dengan jumlah tersebut bisa di bilang sangat sedikit. Postingan yang dilakukan dalam sehari 3 kali ini berjarak antara 4 sampai 5 hari, postingan yang dilakukan dalam sehari sebanyak 3 kali bisa dihitung sedikitnya, hal ini terkendala dari sumber daya manusia dalam mengelola media social. Dinas Pariwisata diharapkan harus lebih giat dalam melakukan branding melalui media sosial, karena sayang sekali jika kecanggihan yang sudah ada pada saat sekarang ini tidak dimanfaatkan dengan baik demi kemajuan sebuah usaha yang ingin di capai.

Dinas Pariwisata terus berupaya melakukan branding melalui media cetak seperti di surat kabar daerah dan provinsi, surat kabar online, buku pariwisata, majalah, pin, shopping bag dan leaflet. Dinas Pariwisata juga sudah melakukan branding melalui media digital seperti di radio pemerintah dan swasta yang ada di Kabupaten Siak.Kemudian Bupati Siak mempromosikan langsung tentang brand Siak The Truly Malay melalui TV One pada tanggal 15 September 2014. Video yang berdurasi selama 30 menit ini berhasi menarik perhatian penonton sebanyak 1.152 kali tayangan. Hal ini di lakukan agar brand tersebut

\footnotetext{
${ }^{13}$ Rakhman Priyatmoko.Tingkat Kesadaran Pramuwisata Terhadap Branding Wonderful Indonesia dan Pesona Indonesia: Strategi Pemasaran Destinasi Pariwisata. Jurnal Destinasi kepariwisataan Indonesia Vol.1.No.1.Juni.2016
} 
lebih dikenal secara luas dan agar Siak berhasil mencapai Image jiwa Melayu yang sebenarnya.

\section{Brand Association}

Dalam melakukan branding Dinas Pariwisata tidak ada menggunakan endorse melalui pihak manapun. mereka masih melakukan branding secara mandiri yaitu melalui media cetak, digital, soisal, event kapariwistataan, instansi pemerintahan dan juga masyarakat setempat yang sadar wisata. Kemudian Dinas Pariwisata menggandeng Bujang Dara Siak yang terbaik di tingkat Kabupaten, Provinsi maupun Nasional dalam melakukan promosi pariwisata yang ada di Siak yang tentunya tak lepas pula untuk mempromosikan brand Siak The Truly Malay.

Asosiasi merek merupakan persepsi dan citra yang dikaitkan oleh orang - orang dengan merek tertentu. ${ }^{14}$ Kesan - kesan yang terkait dengan brand Siak The Truly Malay yang di tonjolkan oleh Dinas pariwisata akan meningkat dengan semakin banyaknya pengalaman pengunjung atau khalayak dalam memahami atau mempersepsi suatu merek atau dengan semakin seringnya penampakan merek tersebut dalam branding, ditambah lagi jika hal tersebut didukung oleh pihak lain yang ada kaitannya. Maka seacara otomatis terbentuklah citra melayu berdasarkan persepsi-persepsi yang di munculkan oleh khalayak yang kenal dengan brand Siak The Truly Malay.

\section{Brand Identity}

Siak kota "Istana" "matahari Timur" itulah sebutan dari Kabupaten Siak, kabupaten yang berdiri tahun 1999 lalu merupakan pecahan dari kabupaten bengkalis. Kabupaten Siak begitu banyak menyimpan berbagai objek wisata yang sangat menarik untuk dikunjungi, mulai dari wisata sejarah, seni, budaya, religious, serta alam yang bergitu asri untuk dipandang. Istana Siak yang merupakan Istana bekas kerajaan Melayu dibangun oleh Sultan Siak ke-11 yakni Sultan Assyaidis Syarief hasyim Abdul Jalil Syaifuddin saat Beliau mulai memimpin Kerajaan Siak pada 1889. Peninggalan sejarah yang bisa di kunjungi di Kabupaten Siak seperti tangsi belanda, balai kerapatan tinggi, makam Sultan Koto Tinggi, Makam Sultan Syarif Kasim, makam Raja kecik, dan makam puteri Kaca Mayang. Selain wisata sejarah, wisata alam, dan buatan Kabupaten Siak juga memiliki destinasi budaya seperti kesenian Melayu, adat, hidangan khas melayu, permainan dan kebiasaan kehidupan masyarakat melayu sehingga Siak layak untuk dikenalkan sebagai "Siak The Truly Malay" yang artinya Siak adalah Melayu yang sebenarnya. ${ }^{15}$

Kemudian kalimat SiakThe Truly Malay tentunya memiliki makna yang sangat mudah untuk dipahami bahwasannya siak itu adalah daerah Melayu yang sebenarnya dan segala bentuk peradaban melayu ada di kota siak. Tidak lupa pula variasi warna yang di tampilkan pada daun sirih dan juga pada kalimat atau tagline Siak The Truly Malay juga dipilih karena warna tersebut merupakan lambang kebesaran kerajaan Melayu dari dahulu hingga sekarang. Jadi sangat jelas jika kita hanya melihat dari brandnya saja, khalayak akan tahu bahwa identitas kota siak yang tergambar dari brand tersebut adalah identitas Melayu.

\section{Brand Image}

Dinas Pariwisata Siak selaku Leading Sector adalah pihak yang paling bertanggung jawab dalam melakukan branding Siak The Trult Malay. Kemudian tak lepas juga dari perhatian pemda dan seluruh instansi pemerintahan setempat karena brand ini merupakan kebijakan pemerintahan.Dinas pariwisata juga menggaet Bujang Dara Kabupaten Siak dalam melakukan branding daerah.Dalam konteks pencitraan kota slogan dan visi kota dapat dipahami sebagai the wish image (citraharapan), citra yang diharapkan dapat diwujudkan dan dimiliki oleh kota tersebut. Bagi kota Siak, slogan atau brand "Siak The Truly Malay"

\footnotetext{
${ }^{14}$ Simamora, Hendri,.ManajemenPemasaran Internasional ( Jakarta :PT Rineka Cipta. 2007)

${ }^{15}$ Data di ambil saat melakukan penelitian di Dinas Priwisata dalam bentuk PowerPoint. 11 Juli 2017
} 
merupakan brand yang dibuat untuk membentuk citra Kota Siak, yaitu menjadikan Siak sebagai Jiwanya Melayu.

\section{Brand Personality}

Merk atau brand merupakan suatu identitas yang merupakan tanda atau ciri yang dipergunakan oleh seorang produsen utnutk membedakan produk yang dihasilkkannya dengan produk pesaingnya.Tanda ataupun ciri ini kemudian membentuk suatu kepribadian yang dikenal dengan brand personality (kepribadian merk). ${ }^{16}$

Istana melambangkan bahwasanya kabupaten siak dahulunya adalah sebuah kerajaan yang sudah berdiri dari tahun 1723 - 1946 M dan menjadi icon Pariwisata Siak sampai saat ini, menunjukkan bahwasanya nuansa sejarah kerajaan melayu yang sangat kuat. Warna kuning, merah, hijau adalah lambang kebesaran Melayu, karena Kerajaan Siak dahulunya adalah kerajaan Melayu terbesar, dimana nuansa Melayu sangat kental dari dahulu hingga sekarang, baik dari segi adat istiadat, tutur bahasa, hingga kehidupan sehari-sehari sampai saat ini. ${ }^{17}$

Lambang daun sirih yang dimodifikasi seperti gelombang menunjukkan bahwasanya kekayaan alam, geografis, kebudayaan, bahkan masyarakat nya adalah suatu kekayaan yang menjadi sumber kehidupan masyarakat kabupaten siak. Siak The Truly Malay memiliki arti siak Melayu yang sebenarnya, menunjukkan bahwasanya segala macam bentuk peradaban melayu ada di siak. Tanda dan ciri tersebut yang merupakan suatu kepribadian yang dikenal dengan brand personality dari brand kota Siak yaitu brand Siak The Truly Malay. ${ }^{18}$

\section{Brand Equity}

Brand equity sendiri mencakup keseluruhan kekuatan dari sebuah merek dipasaran dan akan memberikan value pada perusahaan/badan usaha yang menghasilkan produk/jasa tersebut. Tugas pemasar disini sangat penting untuk dapat membuat rancangan ataupun strategi yang tepat dalam pembuatan identitas merek yang mudah diingat dan memiliki asetaset yang kuat di masyarakat. ${ }^{19}$. Penyusunan kegiatan branding yang sudah dilakukan oleh pihak Dinas Pariwisata agar brand tersebut menjadi kuat adalah mensosialisaikan brand tersebut di dalam dan luar daerah, menampilkan stiker di mobil-mobil pribadi dan dinas, memajangkan spanduk dan baliho di tempat yang strategis, branding melalui media social.Kegiatan Dinas Pariwisata yang sudah membuahkan hasil yaitu Siak dikenal dengan Image Melayu, kebiasaan masyarakat melayu yang mulai pudar sudah kembali dilestarikan, kemudian meningkatnya kunjungan wisatawan local maupun asing di Provinsi Riau.

Setelah peneliti melakukan observasi, wawancara serta mendapatkan dokumentasi dari dinas Pariwisata Kabupaten Siak tentang Strategi Branding Siak The Truly Malay. Observasi dilakukan dengan cara mengamati tentang Strategi Branding Siak The Truly Malay Oleh Dinas Pariwisata Kabupaten Siak dan wawancara dengan beberapa informan guna memperkuat data dari hasil pengamatan dilapangan. Selanjutnya, peneliti akan memaparkan pembahasan tetang Strategi Branding Siak The Truly Malay oleh Dinas Pariwisata Kabupaten Siakdalam kegiatan branding yaitu mengacu pada konsep Brand Awareness, Association, Identity, Image, Personality, dan Equity.

\section{Brand awareness}

\footnotetext{
${ }^{16}$ Hari Mulyadi. Pengaruh Brand Personality TerhadapLoyalitas Pelanggan Sampo Sunsilk.Jurnal Strategic, Volume 7, Nomor 13, Februari 2008

${ }^{17}$ Dat riset. Keterangan BrandSiak The Truly Malay dalam bentuk PowerPoint. 11Juli 2017

${ }^{18}$ Dat Riset. Keterangan Brand Siak The Truly Malay. dalam bentuk PowerPoint. 11Juli 2017

${ }^{19}$ Kadarisman Hidayat. Pengaruh Brand Equity Terhadap Keputusan Pembelian (Survei Pada Konsumen Pembeli Dan Pengguna Kartu Perdana Simpati Telkomsel Di Lingkungan Mahasiswa Jurusan Administrasi Bisnis Angkatan 2012 \& 2013 Fakultas Ilmu Administrasi Universitas Brawijaya Malang). Jurnal Administrasi Bisnis (JAB)|Vol. 34 No. 1 Mei 2016
} 
Brand awareness diartikan sebagai kesanggupan seorang calon pembeli untuk mengenali, mengingat kembali suatu merek sebagai bagian dari suatu kategori produk tertentu. $^{20}$ Dinas Pariwisata Kabupaten Siak memunculkan icon Siak sebagai pusat budaya Melayu dengan brand Siak The Truly Malay. Dinas Pariwisata merasa brand ini layak di kenalkan ke masyarakat. Media yang digunakan antara lain koran, barosur, leaflet, buku profil pariwisata, spanduk, stiker, pamphlet dan media social yaitu facebook, twitter, instagram, Web, YouTube. Selain itu melalui event-event kebudayaan dan olahraga seperti festival Zapin Nusantara yang mencakup beberapa Negara, kemudian festival Siak Bermadah, festival Kuliner Melayu, Pawai Budaya Tingkat Nasional dan Internasional, festival Gasing Internasional, Tourde Siak, BMX Asian, Sepatu Roda.

\section{Brand Association}

Dalam melakukan branding Dinas Pariwisata Siak tidak menggunakan endorse melalui pihak manapun. mereka masih melakukan branding secara mandiri yaitu melalui media cetak, digital, soisal, event kapariwistataan, intasi pemerintahan dan juga masyarakat setempat yang sadar wisata. Kemudian Dinas Pariwisata menggandeng Bujang Dara Siak dalam melakukan promosi untuk mempromosikan brand Siak The Truly Malay. Simbol identik yang terdapat dalam brand Siak The Truly Malay yang menjadi ciri khas Kabupaten Siak yaitu Istana Kerajaan dan Daun Sirih dimodifikasi dengan bentuk gelombang yang sarat akan makna mengenai kehidupan masyarakat Siak yang kemudian khalayak mudah untuk mempersepsikan pesan apa yang dimunculkan dari brand tersebut.

\section{Brand Identity}

Salah satu elemen dalam brand identity menyebutkan bahwaKisah merk dapat menjadi lebih dan lebih penting dalam kehidupan perusahaan. Sebagai suatu konsep, kisah bahkan memenangkan tempat berpijak yang penting dalam perdebatan tentang carabrand masa depan akan di bentuk. Jika Anda ingin brand menjadi benar-benar spesial, Anda perlu memiliki kisah semacam legenda tentang bagaimana perusahaan di mulai. ${ }^{21}$. Siak kota "Istana"Matahari Timur" itulah sebutan dari Kabupaten Siak yang merupakan Istana bekas kerajaan Melayu dibangun oleh Sultan Siak ke-11 yakni Sultan Assyaidis Syarief hasyim Abdul Jalil Syaifuddin saat Beliau mulai memimpin Kerajaan Siak pada 1889. Peninggalan sejarah yang bisa di kunjungi di Kabupaten Siak seperti tangsi belanda, balai kerapatan tinggi, makam Sultan Koto Tinggi, Makam Sultan Syarif Kasim, makam Raja kecik, dan makam puteri Kaca Mayang. Selain wisata sejarah, wisata alam, dan buatan Kabupaten Siak juga memiliki destinasi budaya seperti kesenian Melayu, adat, hidangan khas melayu, permainan dan kebiasaan kehidupan masyarakat melayu sehingga Siak layak untuk dikenalkan sebagai "Siak The Truly Malay" yang artinya Siak adalah Melayu yang sebenarnya. $^{22}$

\section{Brand Image}

Dinas Pariwisatan terus giat menargetkan pencapaian Image Melayu. Meskipun image daerah siak sebagai peradaban Melayu yang sebenarnya belum di kenal diseluruh daerah Indonesia. Dinas Pariwisata Siak selaku Leading Sector adalah pihak yang paling

\footnotetext{
${ }^{20}$ Rakhman Priyatmoko.Tingkat Kesadaran Pramuwisata Terhadap Branding Wonderful Indonesia dan Pesona Indonesia: Strategi Pemasaran Destinasi Pariwisata. Jurnal Destinasi kepariwisataan Indonesia Vol.1.No.1.Juni.2016

${ }^{21}$ Diah Dharmayanti. Pengaruh Brand Identity Terhadap Timbulnya BrandPreferencedan Repurchase Intention Pada Merek Toyota. Jurnal Manajemen Pemasaran Petra Vol. 2, No. 1, (2014)

${ }^{22}$ Data di ambil saat melakukan penelitian di Dinas Priwisata dalam bentuk PowerPoint. 11 Juli 2017
} 
bertanggung jawab dalam melakukan branding Siak The Trult Malay serta Pemerintah daerah. Brand Siak The Truly Malay resmi dipatenkan dan tercatat sebagai hak cipta milik Pemkab Siak oleh Kementrian Hukum dan Hak Asasi Manusia Direktorat hak Cipta dan Desain Industri. Dalam konteks pencitraan kota slogan dan visi kota dapat dipahami sebagai the wish image (citra harapan), citra yang diharapkan dapat diwujudkan dan dimiliki oleh kota tersebut. Bagi kota Siak, slogan atau brand "Siak The Truly Malay" merupakan brand yang dibuat untuk membentuk citra Kota Siak menjadikan Siak sebagai Jiwanya Melayu.

\section{Brand Personality}

Brand merupakan suatu identitas yang merupakan tanda atau ciri yang dipergunakan oleh seorang produsen untuk membedakan produk yang dihasilkkannya dengan produk pesaingnya.Tanda ini kemudian membentuk suatu kepribadian yang dikenal dengan brand personality (kepribadian merk). ${ }^{23}$.Istana melambangkan bahwasanya kabupaten siak dahulunya adalah sebuah kerajaan yang sudah berdiri dari tahun 1723 - 1946 masehi, dan menjadi icon pariwisata Siak sampai saat ini, menunjukkan bahwasanya nuansa sejarah kerajaan melayu yang sangat kuat.Kerajaan Siak dahulunya adalah kerajaan Melayu terbesar, dimana nuansa Melayu sangat kental dari dahulu hingga sekarang, baik dari segi adat istiadat, tutur bahasa, hingga kehidupan sehari-sehari sampai saat ini. ${ }^{24}$ Lambang daun sirih yang dimodifikasi seperti gelombang menunjukkan bahwasanya kekayaan alam, geografis, kebudayaan, bahkan masyarakat nya adalah suatu kekayaan yang menjadi sumber kehidupan masyarakat kabupaten siak. Siak The Truly Malay memiliki arti siak Melayu yang sebenarnya, menunjukkan bahwasanya segala macam bentuk peradaban melayu ada di siak. Tanda dan ciri tersebut yang merupakan suatu kepribadian yang dikenal dengan brand personality dari brand kota Siak yaitu brand Siak The Truly Malay.

\section{Brand Equity}

Ekuitas merek adalah seperangkat asset dan liabilitas merek yang berkaitan dengan suatu merek, nama dan simbolnya, yang menambah atau melindungi nilai yang diberikan oleh sebuah barang atau jasa kepada konsumen. Jika nama atau simbol suatu merek berubah, maka beberapa atau bahkan semua aset dapat berubah atau bahkan hilang, walaupun beberapa diantaranya bergeser kenama atau simbol yang baru. Brand equity sendiri mencakup keseluruhan kekuatan dari sebuah merek dipasaran dan akan memberikan value pada perusahaan/badan usaha yang menghasilkan produk/jasa tersebut. Tugas pemasar sangat penting untuk dapat membuat rancangan strategi yang tepat dalam pembuatan identitas merek yang mudah diingat dan memiliki aset-aset yang kuat di masyarakat. ${ }^{25}$ Hasil dari kegiatan yang sudah dijalankan oleh Dinas Pariwisata paling besar yang sudah diraih yaitu bahwa siak dikenal dengan image Melayu, kebiasaan masyarakat melayu yang mulai pudar sudah kembali dilestarikan, kemudian meningkatnya kunjungan wisatawan local maupun asing, dan menjadi tempat wisata tujuan utama di Provinsi Riau.

\section{Kesimpulan}

\footnotetext{
${ }^{23}$ Hari Mulyadi. Pengaruh Brand Personality TerhadapLoyalitas Pelanggan Sampo Sunsilk.Jurnal Strategic, Volume 7, Nomor 13, Februari 2008

${ }^{24}$ Dat riset. Keterangan BrandSiak The Truly Malay dalam bentuk PowerPoint. 11Juli 2017

${ }^{25}$ Kadarisman Hidayat. Pengaruh Brand Equity Terhadap Keputusan Pembelian (Survei Pada Konsumen Pembeli Dan Pengguna Kartu Perdana Simpati Telkomsel Di Lingkungan Mahasiswa Jurusan Administrasi Bisnis Angkatan 2012 \& 2013 Fakultas Ilmu Administrasi Universitas Brawijaya Malang). Jurnal Administrasi Bisnis (JAB)|Vol. 34 No. 1 Mei 2016
} 
Strategi Branding Siak The Truly Malay yang dilaksanakan oleh Dinas Pariwisata Kabupaten Siak dengan beberapa strategi yang dimanfaatkan dalam kegiatan branding yaitu mengacu pada konsep Brand Awareness, memperkenalkan agar khalayak sadar adanya Branding Siak The Truly Malay yang dilaksanakan oleh Dinas Pariwisata Kabupaten Siak. Brand Association, Dinas Pariwisata melakukan kegiatan melalui media cetak, digital, sosial, event kapariwistataan,olahraga, melibatkan Bujang Dara Siak.Brand Identity, yang di tonjolkan dari brand tersebut yaitu identitas Melayu. Brand Image, Pencapaian Image Melayu yang sudah diberi hak cipta oleh Kementrian Hukum dan Hak Asasi Manusia Direktorat hak Cipta dan Desain Industri. Brand Personality,

\section{Saran}

1. Pihak Dinas Pariwisata Kabupaten Siak harus lebih inovatif dan kreatif dalammenjalankan kegiatan branding agar brand Siak The Truly Malay lebih mudah di kenal dan khalayak dimana saja sadar bahwa Siak memiliki branding yang unik

2. Dinas Pariwisata harus menumbuhkan kesadaran kepada masyarakat untuk membangkitkan kembali kebudayan hidup Melayu yang sudah pudar, karena "Siak The Truly Malay" dibuat untuk membentuk citra Kota Siak, yaitu menjadikan Siak sebagai Jiwanya Melayu. Maka dari itu untuk mencapai hal tersebut harus di mulai dari masyarakat dari Kabupaten Siak Sendiri.

3. Dinas Pariwisata harus sering memperbaharui postingan di media sosial dan harus memiliki akun youtube pribadi dan pengelolaan yang baik akan membuat brand tersebut menjadi lebih dikenal secara luas.

\section{Daftar pustaka}

Dinas Pariwisata Pemuda dan Olahraga Kabupaten Siak..Kajian Pengembangan Objek Pariwisata Unggulan di Kabupaten Siak. (Pekanbaru.PT.WastuAsrindo Riau, 2012).9

Dinas Pariwisata Kabupaten Siak. Data Jumlah Kujungan di Siak.Data Prariset Berbentuk PowerPoint. 11 januri 2017

Dinas Pariwisata Kabupaten Siak. Strategi Branding Siak The Truly Malay. Data Prariset Berbentuk PowerPoint. 11 januari 2017

Data riset. Keterangan BrandSiak The Truly Malay dalam bentuk PowerPoint. 11Juli 2017

Diah Dharmayanti. Pengaruh Brand Identity Terhadap Timbulnya BrandPreferencedan Repurchase Intention Pada Merek Toyota. Jurnal Manajemen Pemasaran Petra Vol. 2, No. 1, (2014)

http://mediacenter.riau.go.id/read/7659/bupati-promosikan-siak-the-truly-malay.html diakses pada tanggal 11 januari 2017 pukul 10:28 Wib

http://mediacenter.riau.go.id/read/7659/bupati-promosikan-siak-the-truly-malay.html diakses pada tanggal 11 Januari 2017 pukul 10:28 Wib

Rakhman Priyatmoko.Tingkat Kesadaran Pramuwisata Terhadap Branding Wonderful Indonesia dan Pesona Indonesia: Strategi Pemasaran Destinasi Pariwisata. Jurnal Destinasi kepariwisataan Indonesia Vol.1.No.1.Juni.2016

Simamora, Hendri,.ManajemenPemasaran Internasional( Jakarta :PT Rineka Cipta. 2007)

Hari Mulyadi. Pengaruh Brand Personality TerhadapLoyalitas Pelanggan Sampo Sunsilk.Jurnal Strategic, Volume 7, Nomor 13, Februari 2008 